\title{
Impacts of the Implementation of ERP Systems on Cash Management: The Redesign of Treasury Processes
}

Bernabé Escobar. University of Seville. Spain. bescobar@us.es

John Cullen. Sheffield Hallam University. UK. j.cullen@shu.ac.uk

José María González. University of Seville. Spain. jgonzalez@us.es

\begin{abstract}
The aim of this paper is to analyze aspects of organizational change induced by using process reengineering to implement new information technology (specifically an ERP system) on treasury department and its processes. Based on an intensive case study, the paper explores the changes in the treasury department of a large Spanish Electricity Company that implemented the SAPR/3 system. The results suggest that change had important repercussions on the technological, organizational and human dimensions of the treasury department. Evidence is also provided of the inter-relationship between these different dimensions.
\end{abstract}

Key words: Cash Management, Business Process Reengineering, ERP Systems.

\section{INTRODUCTION}

Any organization, big or small, with or without a profit motive, public or private, manages the monetary flows which take place in the development of its activity. Since these flows are essential for the correct working of any organization, Cash Management (henceforth, CM) has become a critical function (Martino, 1998). 
Additionally, we view Management Accounting in a broad sense, as an information system that must supply relevant information to the business managers. So, CM would be included in this definition, since it represents a properly constituted management activity that looks after monetary flows. Likewise, Management Accounting is not an independent department in the organization with strictly defined limits and a role independent of the ones developed by other functions, but it extends through all the organization, impacting on different organizational levels and areas, and supplies with them information for their planning and control tasks.

Basically, CM aims to invest monetary funds when there are surpluses and to obtain them when there are deficits (Helliar, 1998). This task is the responsibility of Treasury Department (henceforth, TD) which has extended its activities (Greifer, 2001), in order to participate more in business strategy development (Phillips, 1997). In this way, TD has evolved from the realization of routine tasks, such as the transactions register and processing, to be a department which makes decisions on monetary flows, financial instruments and risks, relationships with the financial entities and investors (Teigen, 2001). In this sense, we can refer to an evolution during the 1980s from an Operative Treasury to a Management Treasury (Torre, 1998; Heywood, 1999).

Several circumstances have contributed to this evolution, among them (Heywood, 2000; Mulligan, 2001): (1) the higher emphasis on the efficient use of capital; (2) the imperative of creating value for the shareholders through an appropriate management of financial risks; (3) the innovation in the financial instruments; and (4) the information technologies (henceforth, IT) advance.

Also, the specialized literature usually highlights the contribution of new IT to the CM centralization in multinational businesses (Large, 2001). In this way, business groups or companies that have got a decentralized CM can opt for centralizing it in order to allow them to obtain a global liquidity position and to optimize the management of their resources.

Among the most extended IT for CM, we can point out treasury software, both specific and standard, electronic banking (Charro and Ortíz, 1996), Internet banking (Wilson, 2001), and ERP systems (Makela, 1999; Brandman, 2000; Thurston, 2000). These technologies have enabled, for example, the development of collection 
and payment instruments for business transactions and the establishment of closer relationships between companies and financial entities.

On the other hand, new IT constitute the critical element of Business Process Reengineering (Davenport, 1993a) whose target is to make drastic improvements in organizational performance through the redesign of business processes. In the 1990s, this concept of reengineering has been the focus of a great deal of attention from researchers representing different disciplines (Earl, 1994). Specifically, Scott (1993), Sagner (1997) and Brazzale and Milligan (1998) highlight the contribution that reengineering can make to the $\mathrm{CM}$ evolution through the improvement of its processes. Nevertheless, the development of a reengineering project implies an organizational change process which has significant repercussions on diverse dimensions of organizations. Furthermore, these repercussions are not always positive and the project may fail (Grover et al., 1995).

In the 1990s, the literature about CM and its evolution enabled by new IT has been developed (Martino, 1998), as well as a widespread literature about business process reengineering (Thong et al., 2003). However, the combined study of both research topics has been scarcely focused as repercussions of organizational change induced by the process reengineering to implement a new IT (specifically an ERP system) on the TD and its processes have not been analyzed in depth. Basically, the specialized literature about $\mathrm{CM}$ and reengineering has focused on the technological dimension of the change, but this literature has not focused on organizational and human dimensions that are also very important to enable successful. In this paper we address this issue by focusing on the $\mathrm{CM}$ centralization process induced by this type of organizational change which now represents a marked trend in business groups (Mulligan, 2001).

In order to achieve our aim, we have structured the paper as follows. The next section outlines the research design and the research process. The third section presents the theoretical approach to $\mathrm{CM}$, the contribution of information technologies to $\mathrm{CM}$ and an analysis of the change process induced by their implementation through a reengineering approach. The fourth and fifth sections describe and analyze, respectively, the case study results of a Spanish electricity company that redesigned its economic-financial processes in order to implement an integrated information system. The sixth section presents some concluding comments and makes suggestions for future research. 


\section{RESEARCH DESIGN}

In order to provide empirical evidence of the change process, we have undertaken a longitudinal case study. Following Pettigrew (1997), we have distinguished several analysis levels (individual, department, organization and business group) and we have analyzed the temporal interconnections of the change process, adopting a holistic perspective. This has allowed us to directly observe the studied organization, to obtain a rich description of the change process and to use multiple sources for collecting evidence over a long period of time, embracing the social, political and historical context of the analyzed phenomenon (Yin, 1987; Scapens, 1990).

The principal information sources were: (1) participant observation, during one year when one of the researchers worked in the TD, (2) 52 semi-structured interviews with employees of the TD and other functional areas (such as Accounting, Commercial, Internal Control, Internal Auditing, Information System, and employees of the parent company), (3) non-participant observation during 3 visits in each month undertaken during the period 1997-2002, (4) the analysis of the information systems together with its users, and (5) informal discussions with employees that were very important as it allowed us to compare the information collected through the formal sources. Also, these informal discussions allowed us to probe deeper into the political, social, historical and organizational context of the studied organization.

In addition to the above sources of data, additional information was gathered from analysis of documents such as the internal journals and bulletins of Energy and Spainfield Group, annual financial reports of these companies, several documents about the new information system, internal documents about the TD, and reports about the CM centralization in the Spainfield Group. We also had access to the Intranet of the organization where we were able to collect news and developments in the organizational change process.

The combination of these sources has contributed to the internal validity (Yin, 1987) of our study, since it has allowed us to triangulate the collected information. 


\section{THEORETICAL APPROACH}

$\mathrm{CM}$ can be defined as "the group of strategic and organizational measures that affects the monetary flows and, by definition, the financial results of an organization" (López, 1996: 15). Since other departments can affect the monetary flows besides TD, López distinguishes between Internal CM which is related to the activities developed by TD, and External CM which relates to the activities carried out by other departments that influence the monetary flows of the organization. In turn, Internal CM can be divided into: (1) Operative CM that incorporates the planning, forecasting and control of the banking conditions and the collection and payment realization; and (2) Financial CM that embraces the liquid funds management, the deficit covering, the surplus investment, the risk hedging and the negotiation with financial entities (Torre, 1998).

TD is responsible for Internal $\mathrm{CM}$ and this justifies its existence as an autonomous department that is separated from Accounting in large organizations (Helliar, 1998).

$\mathrm{CM}$ is mainly characterized by constituting a management in value date that rests in three pillars: (1) the negotiation, both with the external agents and with other departments of the organization; (2) the control, both of data on its transactions that have been registered by financial entities and of the accuracy of its cash forecasts; and (3) the information that must be as accurate and current as possible. This management in value date allows the TD to obtain the liquidity position that reflects the cash funds that are available for the organization to meet its payment commitments.

In the case of business groups, organizations can obtain a global liquidity position through the centralization of their CM processes. Likewise, the CM centralization can provide the parent company with more information and increased control on the CM carried out by the subsidiaries, as well as a reduction of the information systems, structure and personnel costs. However, centralization incurs additional costs such as the necessary investment for its implementation (Mulligan, 2001).

In order to understand the nature of $\mathrm{CM}$ centralization in business groups, Torre (1998) uses two criterions to distinguish four centralization conceptual models: 
(1) the concentration grade of Operative CM and (2) the centralization grade of Financial CM, as the activities that are embraced by each type of CM are carried out by the different subsidiaries or by a Treasury centre for the whole group (see figure 1 below). In this way, Operative CM is said to be deconcentrated when the activities that it embraces are carried out by the different subsidiaries. Alternatively, if these activities are carried out by a Treasury centre, Operative CM is said to be concentrated. The same is applicable to Financial CM in terms of decentralized or centralized Financial CM, respectively.

\begin{tabular}{|c|c|c|c|}
\hline \multicolumn{2}{|c|}{} & \multicolumn{2}{|c|}{ Operative CM } \\
\cline { 3 - 4 } & Decentralized & Deconcentrated and decentralized CM & Concentrated \\
\hline \multirow{3}{*}{$\begin{array}{c}\text { Financial } \\
\mathrm{CM}\end{array}$} & Centralized & Deconcentrated and decentralized CM \\
\cline { 2 - 4 } & & Concentrated and centralized CM \\
\hline
\end{tabular}

Figure 1. Conceptual models of treasury centralization (Torre, 1998).

Besides these conceptual models, we can distinguish three other structural ones for the centralization of TD activities: (1) Treasury Coordination, in which the TD of the parent society establishes the guidelines that must be followed by the TD of the group subsidiaries; (2) Treasury Unification, where the TD of the parent society manages the Treasury of the group while the subsidiaries either don't have their own TD or their powers are significantly reduced; and (3) Treasury Shared Services Centre which is a centre independent of the parent society that carries out CM for the whole group (Malcolm, 1999).

The new IT, such as treasury software, electronic banking, Internet banking and ERP systems, are allowing business groups to carry out the CM centralization. Among the approaches that can be used to implement this new IT, the process reengineering has achieved a wider diffusion between organizations in the 1990s. This approach is characterized for being (Hammer and Champy, 1993; Hammer and Stanton, 1995): (1) fundamental, since it enables the analysis of the rules in which the management of the organization operates; (2) radical, since it rejects the current processes and begins again; (3) spectacular, where implemented, organizations get a quantitative leap in their performance; and (4) processes, because the reengineering focuses on these and not on the organizational functions. 
The implementation of redesigned processes based on new IT introduces radical organizational change that is manifested in different dimensions (Davenport, 1993b): (1) technological, as it proposes the introduction of new information technologies and the re-structuring of different enterprise information systems; (2) organizational, through hierarchical structure levelling, changes in organizational culture favouring innovation, measures and incentives implementation, management by processes, the employees empowerment, etc.; and (3) human, as employees will experience changes in their working way, roles and responsibilities, decisions making, norms and values, etc.

Due to the importance of IT to the CM development and the contribution that IT can make through the reengineering, we consider that is necessary to provide a richer description of the processes at work, mainly in relation to the organizational and social aspects implied in the organizational change that is generated.

\section{THE CASE OF ENERGY}

Energy (alias of a real organization) was chosen by us for two main reasons: (1) its relevance in the Spanish business structure; and (2) its adaptation to the purpose of our research, since the TD of Energy had to redesign its CM processes to implement the SAP R/3 system, and this caused significant changes in this Department during the period of investigation.

Energy operated in the Spanish Electricity Sector which initiated its liberalization process when the Electricity Sector Law was approved in 1997. To confront the bigger competence in the sector, Spainfield Group acquired several Spanish electricity companies, Energy among them, and implemented the SAPR/3 system in the economic-financial area of its subsidiaries. The Spainfield Group purpose was to constitute an integrated industrial group and in order to do this, the Group adopted a reengineering approach.

In the next sections, we make reference in chronological order to the most important changes that the TD of Energy confronted between 1996 and 2002 and their repercussions. These changes were: the implementation of System-Cash, the implementation of the treasury SAP R/3 module, and the implementation of the Concentr@ Project (see figure 2). 


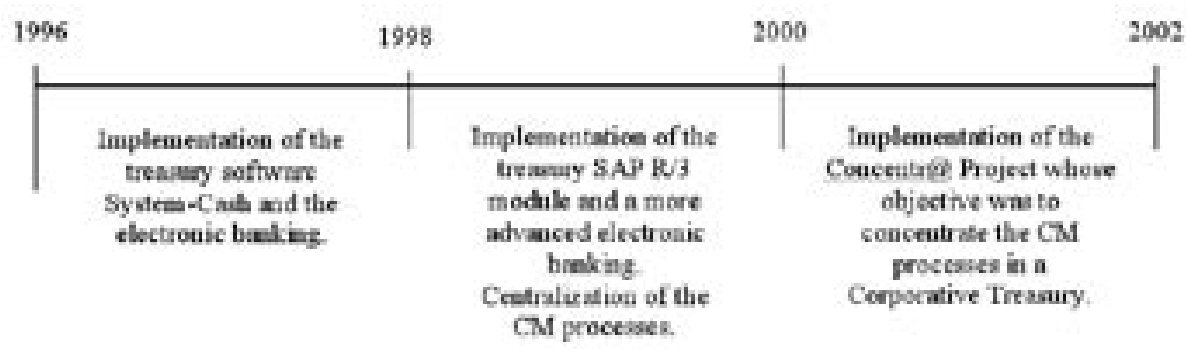

Figure 2. Organizational changes in the TD of Energy

\subsection{Implementation of system-cash}

The TD was a part of the Financial Area which itself was located within the Economic and Financial General Direction of Energy. This TD shared the Energy organizational culture that was mainly paternalistic. In this sense, the employees enjoyed stable jobs with good salaries and good working conditions. They were proud of being part of Energy and, therefore, very loyal and patriotic to the company.

A treasury standard software was implemented in the TD of Energy at the beginning of 1996. This application, which was called System-Cash, was requested by the employees themselves to automate and to speed up their activities. The receipt of the payment and collection data that came from other departments ${ }^{1}$ was obtained through interfaces designed to this effect, while electronic banking was implemented for communication with financial entities.

Therefore, the CM of Energy was supported by this system that resulted in several advantages, among them: (1) the activities automation, like the data record or interests liquidation control; (2) an increase of the percentage of reconciled data, since the system incorporated new reconciliation modalities and it enabled consideration of more parameters than the previous system; (3) the possibility of analyzing and simulating transfers in the credit policies management, as well as to simulate operations in short and long term financing or investment with the consideration of different types of treasury forecasts; (4) the supply of more complete information that could be electronically processed; and (5) the increased speed of information access, mainly due to electronic banking.

1 Mainly Commercial, Internal Control and Personnel. 
The CM processes of Energy with System-Cash were as follows: (1) Bank reconciliation which was exclusively carried out by TD starting from the data supplied by financial entities and the recorded ones in the Energy accounting system; (2) Record of bank data in the accounting system which was another application independent of the treasury one; (3) Treasury position management which supported the management of credit policies balances and carrying out the credit transfers between banks to optimize them; (4) Control of bank spending, mainly the commissions and interests by disposed balances; (5) Negotiation with financial entities, from the credit policies conditions that Energy had subscribed (on the whole 17 policies with the same number of financial entities by an amount of 273.47 million euros), until the auctions between financial entities to pay the taxes and Social Security; and (6) Elaboration and revision of treasury budget starting from historic information and the forecasts of TD and other departments that carried out collections and payments.

\subsection{Implementation of the treasury $S A P R / 3$ module}

In spite of the employee satisfaction with System-Cash, when Energy was acquired by Spainfield Group, Spainfield forced its subsidiaries to implement $\mathrm{SAP} R / 3$. This project was developed in the TD by a tripartite team that operated from the beginning of 1998 to the beginning of 1999. This team consisted of a computer specialist of Energy, a SAP consultant and an user of the TD and they were supported by a centralized team in the parent society of Spainfield Group. The conceptual design of the new treasury system and the process redesign were carried out by this team, although this task was limited by the preset functionalities of SAP R/3. In this respect, for instance, the new treasury system didn't envisage that the bank extracts weren't electronically received, since this wasn't important for other subsidiaries of the Spainfield Group in which the clients domiciliation was about $100 \%$. However, this fact was important for Energy due to the habits of its clients, mainly in the rural areas².

\footnotetext{
2 At the end of the 1990s, about 30\% of Energy clients weren't domiciliated. Most of rural areas clients traditionally paid their receipts at the paying-in desk at their Saving Banks which didn't have connection to electronic bank and, therefore, this information was supplied by Commercial on a magnetic tape. In this sense, an interviewee suggested that "this problem continued after the SAP implementation until Spainfield Group undertook the Zero Metallic Project which promoted the domiciliation and added another specific utility".
} 
Also, as the treasury SAP module had been previously developed by a subsidiary of the Group, the parent society decided to modify it to incorporate better practices and to adapt it to the different subsidiaries. On the other hand, the Energy employees' participation in the project was limited to their training on the new system and its utilization. In this respect, a member of the team responsible for the SAP R/3 implementation noted that "for the SAP R/3 implementation, the direct opinion of the users has not been considered. Basically, the change has been imposed on the employees. That is to say, they told the employees this is what there is and therefore take it".

After the SAP R/3 implementation, the CM was centralized in the TD of the parent society that began to establish the guidelines that should be followed by the subsidiaries. In this way, the processes carried out by TD of Energy were structured in:

(1) Reception, accountancy and reconciliation of bank extracts. The reconciliation was carried out in a decentralized way by the TD and other departments that were involved in collections and payments. The previous interfaces among these departments were eliminated since they owned the same technological platform. This also meant, for example, that the TD didn't have to export its data to the accounting system, as once these data were recorded in the treasury SAP $\mathrm{R} / 3$ module, these data were available to the rest of the departments.

(2) Treasury position and estimate. The TD of Energy had to communicate to the parent society daily the forecasted treasury position and it had to make some punctual funds transfers to rectify any treasury deficits in the Group.

(3) Bank funds movements to optimize the credit policies balances. Energy reduced the number of financial entities and the total amount of the subscribed credit policies which diminished up to 42.67 million euros. This reduced the margin of manoeuvre of the TD of Energy quite a lot.

(4) Guarantees management. This new process was assigned to TD and it consisted of managing the subscribed guarantees lines for the obligations guarantee, mainly relating to work-in-progress.

(5) Detailed management reports, for instance, about bank risk and the bankenterprise business, middle balances by value date, not reconciled data, forecasts 
by financial entity, interest liquidations, made credit transfers, guarantees by financial entity, etc. These reports were remitted to the TD of the parent society. Also, this department took the responsibility for both the bank negotiation for all the subsidiaries of the Group (establishing the guarantees and credit policies, current accounts, interest rates, commissions, payment auctions, etc.), and the treasury budgets elaboration.

At the beginning, the employees of the TD argued that the treasury SAP R/3 module was no more than " a forced adaptation of the System-Cash they were using at the time". Some errors of the SAP R/3 such as duplication of data, problems with the codes assignment to the data, and loss of some data which occurred in the first few months of the change reinforced this criticism. These problems were gradually solved by the tripartite team and the users recognized finally that the SAP module was superior to System-Cash. They recognized that SAP enabled the TD to have a higher integration with the rest of organizational areas and the homogenization of its processes at Group level. Some more specific improvements were: (1) the reconciliation process efficiency increment, since "it passed from the $85 \%$ of reconciled data with System-Cash to the $99 \%$ of ones with SAP due to the fixation of an interval for the amount and/or value date of the data to reconcile"; (2) a more advanced system of electronic banking; (3) the reduction of the processes execution time, in support of this an interviewee affirmed that "before, with SystemCash, the management of a banking account had an approximate duration of one hour. Now, with SAP R/3, the duration is a quarter of hour per each account. With SAP R/3, the banking accounts management is reduced to the assignment of codes to the data which aren't automatically recorded". Likewise, with regard to the optimization of the credit policies balances, this interviewee expressed that "with System-Cash, we had to integrate the banking data and sometimes the treasury position was obtained after $12 o^{\prime}$ 'clock. This prevented the transfer of funds between financial entities through the Bank of Spain. With SAP, due to the higher automation of the data record, the treasury position is obtained about 10 o'clock and then we have time to make the transfers"; and (4) the higher automation of the transactions processing, in particular, "approximately 150,000 data were annually recorded in System-Cash. Around 8\% of them were manually recorded. With SAP, these were reduced below 1\%". Also, unlike with System-Cash, the treasury SAP module "automatically generates the necessary mail to carry out the funds transfers between financial entities". 
The SAP implementation and the centralization of $\mathrm{CM}$ caused a reduction in job content and resulted in a loss of autonomy experienced by the employees of the TD of Energy. However, the interviewees that were asked about this question ${ }^{3}$ did highlight some centralization benefits, among them:

a.- The personnel costs reduction. In 1997, Spainfield Group began its Plan of Costs Reduction which estimated a personnel costs decrease of 361 million euros for the period 1997-2002 and this required a personnel progressive adjustment. At the end of 1999, an accumulated reduction of 278 million euros had been achieved by the Group. This resulted in a decision to enlarge the plan until 2003 to reduce the personnel costs even more (Report on consolidated results of Spainfield Group on December 31, 1999). Obviously, this reduction can't be exclusively attributed to the ERP system implementation, but this was a decisive factor that ensured that the personnel reduction didn't harm the Spainfield Group and its Treasury.

b.- The development and licence cost saving of the system, since Spainfield Group had to pay only one system licence and the computer specialists of the Group had to maintain and develop only one system instead of maintaining different systems for the eight subsidiaries of the Group. Likewise, the SAP R/3 implementation allowed the subsidiaries to confront the Effect 2000 and the change to the euro. This enabled a cost saving of 7.5 million euros for the Group (Internal Document of Spainfield Group).

c.- The optimization of the organizational resources couldn't be quantified, since it was due to different changes which simultaneously took place (personnel reduction, informatics systems implantation, reorganization of the Group by business lines, functions centralization). However, the interviewees argued that "it is not the same thing to maintain 8 treasury departments, with their respective office spaces, computers, personnel teams, etc., than to have a treasury department for the whole Group".

d.- A centralized management which established uniform criterions for the whole Spainfield Group, mainly in respect to the reporting of the subsidiaries back

\footnotetext{
3 Specifically, a manager of the Finance Function, a superior graduate and two office workers of the TD of Energy.
} 
to the parent society, for instance, the codes used for the different accounts, the reports rhythm, format and content.

e.- A higher power to negotiate with suppliers and financial entities. This allowed the Spainfield Group, for instance, to subscribe to several multi-enterprise and multi-currency credit lines covering the long term for a total of 4,358 million euros with a group of financial entities. Also, "the Group got to reduce the banking commissions and the interests, both for disposed funds and for exceeded funds of the credit policies".

\subsection{Implementation of the Concentr@ Project}

In 2000, the Spainfield Group concentrated its CM processes in the TD of the parent society which was constituted as a Corporate Treasury. At the same time, the TD of the subsidiaries practically disappeared. The CM processes were carried out by this centralized Corporate Treasury that dealt with all of the processes from the reconciliation and the negotiation with financial entities up to the banking funds transfers and the obtaining of a treasury position for the whole Group instead of a treasury position by each subsidiary. In this respect, according to the person responsible for the concentration project, "we try to share all these services so that the clients, who are the people and subsidiaries of Spainfield, don't need to have their own economic-financial departments, since this results in the dispersal of efforts and the loss of efficacy. In this way, the subsidiaries can stop worrying about how they should carry out the accounting or maintain their treasury position, as they neither worry about the management of their information systems or the provisioning of materials and services" (Internal Journal of Spainfield Group, $n$. 117: 30).

During the centralization process, first, and the concentration process, later, the employees of the TD of Energy experienced feelings of anguish and impotence, loss of bonding, conformism, resentment, etc. In this sense, an interviewee argued that "we are feeling ourselves abandoned during the changes which are taking place. The company is no longer paternalistic. The employees are not identified by their names but rather by their password. The company has been totally impersonalized. Now, we are no longer important to them". Since the TD of Energy was going to disappear, its employees had to leave: four employees opted for the "voluntary" 
early retirement, since they were 50 years old or more and four employees were relocated to other departments ${ }^{4}$. The principal destination of the relocated employees was the Collections and Billing Centre of the Group.

\section{DISCUSSION}

According to the CM classification elaborated by López (1996), we can say that the TD of Energy was responsible for Internal CM of the organization, while Commercial, Internal Control and Personnel carried out the External CM, since they also impacted on the monetary flows of Energy.

The requirement of the employees of the TD of Energy to carry out the Internal CM was satisfied by System-Cash. However, when Energy was acquired by Spainfield Group, the implementation of the treasury SAP R/3 module was necessary, as the Group wanted to get the operative integration and the step forward was the constitution of a Corporate Treasury which was responsible for the CM of the Group.

Spainfield Group adopted a reengineering approach to implement the treasury SAP R/3 module. Following Hammer and Champy (1993), the reengineering was: (1) fundamental, since the rules relating to the $\mathrm{CM}$ of the subsidiaries were analyzed and they were modified to get homogenization; (2) spectacular, since the efficiency of the Treasury at group level was improved significantly and this was reflected in the CM processes improvement with a lower costs (of personnel and system license and development) ${ }^{5}$; (3) focused on the Treasury processes and on the different activities which compose these processes; and (4) radical, but not at the level indicated by these authors, as the new processes were adjusted to the new system and their redesign didn't involve reinvention of the CM.

The reengineering carried out by the Spainfield Group induced an organizational change that had significant repercussions on the three dimensions pointed out by

\footnotetext{
4 Three graduates and one office worker were relocated. Other four office workers retired themselves.

5 We haven't been able to get quantitative data, but an interviewee commented that "at the beginning, each subsidiary had a TD with its own system and its own personnel. These departments worked in an independent way. After, the Group changed to have only one TD for the whole Group, this resulted in structure cost savings, system cost savings and personnel cost savings".
} 
Davenport (1993b): technological, organizational and human. We refer to the different repercussions on these dimensions in the next sections.

\subsection{Repercussions on the technological dimension}

In respect to technological dimension, IT was very important to the CM development of Energy and the Spainfield Group (Martino, 1998; Makela, 1999; Thurston, 2000), specifically:

a.- Electronic banking enabled a more agile and online communication with the financial entities.

b.- Treasury standard software such as System-Cash automated many activities of the TD, reduced their realization time and improved their efficiency. In this sense, the previous system to System-Cash was SGAT and this system only completed the banking reconciliation in a very rudimentary way ${ }^{6}$. System-Cash allowed: (1) a more advanced banking reconciliation, as it incorporated a multibanks electronic banking system and three reconciliation modalities (single automatic, advanced automatic and manual), that increased the reconciliation percentage from 60 to $90 \%$; (2) a higher integration with the rest of the systems of the different departments of Energy; (3) the automatic recording of most of the data; (4) the mechanization of new activities such as the interests liquidation control; (5) the digital processing of the information; and (6) higher speed in information accesses, mainly due to the information networks and electronic banking. Likewise, System-Cash contained analysis and simulation tools: to manage the credit policies balances, that allowed a reduction in the financial costs; to simulate future scenarios through the variance of the interest rates, exchange rates, credit policies conditions, etc.; and to simulate transactions involving short and long term financing and investment according to the collections and payments forecasts.

c.- The ERP system such as SAP R/3 improved the communication of the $\mathrm{TD}$, as it reduced the interfaces and integrated the treasury system in the same technological platform that was possessed by the rest of the Financial Function.

6 SGAT had only a primitive reconciliation modality with scarce parameters to confront the data, resulting in a lower percentage of reconciliation. 
This system homogenized the treasury processes and increased their efficiency at group level. For it, Spainfield Group utilized internal benchmarking that can be considered to be a key reengineering tool (Furey, 1993; Harrison and Pratt, 1993; Ruchala, 1995). In this sense, the reengineering team analyzed the systems of each subsidiary, compared the way in which each one developed the different treasury activities and chose the most appropriate system (see table 1 below). The chosen system belonged to a subsidiary which had implemented some specific developments in the treasury SAP R/3 module. As a consequence, the Spainfield Group got the treasury system unification that in turn allowed the homogenization of its processes and the information integration.

\begin{tabular}{|c|c|}
\hline \multicolumn{2}{|r|}{ Reception, accountancy and reconciliation of bank extract } \\
\hline Energy & $\begin{array}{l}\text { The extracts are received to compare the banking information with the enterprise } \\
\text { accounting. The identified data and some special ones (Telefónica, accounts sweeping) are } \\
\text { automatically counted. }\end{array}$ \\
\hline Subsidiary X & All the extracts are counted. \\
\hline Subsidiary Y & $\begin{array}{c}\text { The extracts are received to compare the banking information with the enterprise } \\
\text { accounting. The identified data and some special ones (Telefónica, accounts sweeping) are } \\
\text { automatically counted. }\end{array}$ \\
\hline Observations & $\begin{array}{c}\text { The Subsidiary X simultaneously carries out the reconciliation and accountancy processes, } \\
\text { while Energy and Subsidiary Y separate both processes, since they are carried out in two } \\
\text { different systems. }\end{array}$ \\
\hline \multicolumn{2}{|r|}{ Treasury position and estimate } \\
\hline Energy & The treasury position is obtained starting from the financial information of the company. \\
\hline Subsidiary X & $\begin{array}{l}\text { The information contained in some transitory accounts is added to the financial } \\
\text { information to get the treasury position. }\end{array}$ \\
\hline Subsidiary Y & $\begin{array}{l}\text { The information of the extracts is compared with the financial information of the company. } \\
\text { Then, the no-counted data are recorded to adjust the treasury position. }\end{array}$ \\
\hline
\end{tabular}

Table 1. Example of internal benchmarking in the treasury practices (Source: Internal Documents of the TD).

The ERP technology allowed the consolidation of the pillars of the CM in value date as signalled by Valls (1996): (1) negotiation, both with the rest of the departments that shared the same information system, and with the financial entities through a more advanced electronic banking. However, the Spainfield Group reduced the number of financial entities with which it operated and this confirms the trend signalled by MacDonald (2001) and Teigen (2001), among others; (2) control, since this technology introduced more sophisticated tools to carry out, for instance, the process of reception, accountancy and reconciliation of bank extracts; and (3) the quasi online information provided by the financial 
entities and other departments of the organization. Besides, this information was available for the whole Group.

\subsection{Repercussions on the organizational dimension}

Also, the implementation of the treasury SAP R/3 module had repercussions on the organizational dimension of the TD of Energy. In the first place, we can highlight a TD separated from Accounting (Helliar, 1998), however they had a close relationship as the banking information was daily exported from System-Cash to the Accounting system. Also, the coordination between both areas increased when SAP R/3 was implemented as they shared the same technological platform.

The CM processes of Energy were centralized in the TD of the Spainfield Group as usually happens in business groups (Large, 2001). At the beginning, following the conceptual models proposed by Torre (1998), the Spainfield Group implemented a deconcentrated and centralized model, as the TD of the subsidiaries continued carrying out the transactions processing and the control (for example, the funds transfers record, the bank reconciliation and the interests liquidation control), while the management activities (for example, the negotiation with financial entities, the deficits covering and the surplus investment) were undertaken by the TD of Spainfield Group which also increased its control on the peripheral TD. This was evident in the wide reporting and the stricter and formalized procedures that these TD had to carry out. The organizational structure adopted to support this treasury conceptual model was Treasury Coordination.

In 2000, the Spainfield Group concentrated the CM processes in the parent society. This supposed a conceptual model change, as the treasury became concentrated and centralized. In this way, the management activities and the transactions processing were carried out by the TD of the parent society. For it, the organizational structure of the Group Treasury evolved toward the Treasury Unification, specifically, toward a Corporate Treasury that caused a drastic reduction of the TD of the subsidiaries at the end of 2001. Later, these departments were definitively suppressed.

In this way, the TD of Energy stopped: (1) receiving the information about the different current accounts by electronic banking and, therefore, recording the 
data in the system; (2) carrying out the transfers between the credit policies to optimize their balances; (3) reconciliating the accounting and banking information; (4) estimating the treasury position of Energy, since now an only treasury position was obtained for the whole Group; and (5) negotiating with financial entities. Starting from then, the Corporate Treasury of Spainfield Group was responsible for all of these activities.

The definitive centralization and concentration of the CM produced significant benefits, but also it resulted in some costs (Mulligan, 2001). The main benefits were:

a.- Elimination of idle balances due to the consolidation of all the treasury positions. The total amount of the credit policies subscribed by Energy was 273.46 million euros ${ }^{7}$. This amount was reduced to 42.67 million euros after the acquisition of Energy by Spainfield Group. This forced the TD of Energy to adjust further the amount of bank to bank funds transfers. Also, Spainfield Group ordered the TD of the subsidiaries that carried out some transfers between them to avoid the deficit positions.

b.- Financial cost savings due to the higher negotiation power of the Group in relation to financial entities, and the structural cost savings, since Spainfield rationalized the treasury organizational structure of the Group. However these savings haven't been able to be quantified due to the impossibility of individualizing the effects of so many simultaneous changes. In the case of the financial costs, an interviewee said to us that: "the debt short interest rate of Spainfield Group was reduced from $6.5 \%$ (in 2000) to $5.85 \%$ (in 2001)".

c.- A more reliable control of liquidity due to the estimation of a global treasury position for the Group. In this sense, an interviewee said that: "Before, the Group had to trust the information that their subsidiaries supplied to it about their current accounts. Now, the parent society is the holder of all the current accounts and it directly disposes of the funds".

\footnotetext{
7 Bank to bank transfers were daily carried out by the TD of Energy to optimize the balances of their credit policies. The daily amount of these transfers rarely surpassed 24 million euros, therefore some credit policies were inactive during weeks and even months because they weren't necessary. However, these credit policies weren't eliminated because, as the head office of the TD said: "They don't cost anything, since they don't have neither opening commissions or disposition commissions. Also, we maintain the relationship with the different financial entities because they can be necessary for us in the future".
} 
On the other hand, the main cost of the CM centralization was the necessity to redesign the processes to implement an information system that supported the model of Corporate Treasury.

\subsection{Repercussions on the human dimension}

As a consequence of the organizational change, most of the interviewees were in particular concerned about Energy's loss of autonomy and the rigidity of the control practiced by the parent company on them. In the same sense, the implementation of the treasury SAP R/3 module and the centralization of $\mathrm{CM}$ also caused a reduction in job content and resulted in a loss of autonomy experienced by the employees of the TD of Energy in their daily decision making. These factors can be identified as costs of the CM centralization (Santomá, 2000; Mulligan, 2001).

Likewise, the employee uncertainty during this period was exacerbated by the limited information provided to the employees about the different organizational changes that were taking place. This limited communication is considered in the specialized literature as a significant generator of resistance to the change in the process reengineering (Stoddard and Jarvenpaa, 1995; Guha et al., 1997).

Some employees of the TD argued that the Spainfield head office had imposed the new system on them without considering their views. They claimed that they were happy with the System-Cash application they were using prior to the takeover and therefore did not see the need for the treasury SAP R/3 module, which replaced the System-Cash application.

Furthermore, the employees' participation in the project was limited to their training on the new system and its utilization. The knowledge and experience of the employees were not incorporated into the design of the new system and this also contributed to generate resistance to the change (Davenport and Perez-Guardado, 1999; Martinsons and Chong; 1999). The computer specialists and SAP consultants focused only on the technological aspects and used the internal benchmarking as the main tools exclusively carried out the internal diagnosis (Ruchala, 1995). As an user expressed, "they have not counted on us, they have not asked for our opinion. A system was bought and implemented, and we have been trained to use it". 
As a consequence of the above, there was resistance to the change during the implementation of the new system. The interviewees noted that, in general, the resistance to the change was higher among older employees than among younger employees. This resistance was mainly demonstrated through absenteeism at the training courses and at the presentations about the new system. The employees however later recognized the superiority of SAP R/3 over System-Cash and therefore accepted it.

Finally, we have to highlight that the paternalistic nature of Energy, the job stability of the employees, the pride the employees have in the organization, were all replaced by a purely professional relationship, insecurity, uncertainty, continuous change and anticipated redundancy and relocations. All these created indifferent feelings among the employees and even resentment towards the organization. The reduction in the employees exacerbated the problem as many veteran employees who had worked in the company for more than 30 years felt betrayed.

\section{CONCLUDING COMMENTS}

Based on our case study, we have provided evidence of the impact of process reengineering to implement new IT, specifically an ERP system, on the TD of an organization and its CM processes. Our evidence shows that the implementation of the treasury SAP R/3 module had significant repercussions not only on the technological dimension, but also the organizational and human dimensions of the TD. Also, there is evidence of inter-relationships between the different dimensions.

With regard to the technological dimension, we demonstrate that the new treasury system was implemented to homogenize the CM processes of the Group and to integrate these processes with the ones carried out by other departments, such as Accounting. Likewise, the treasury SAP R/3 module allowed, among other things, an increase in the efficiency of the $\mathrm{CM}$ processes and a consolidation of the pillars of the $\mathrm{CM}$ in value date, that is to say, negotiation, control and online information.

Regarding the organizational dimension, the new treasury system facilitated the change of the treasury conceptual model as the Group changed from a deconcentrated and centralized model to a concentrated and centralized model of $\mathrm{CM}$. Also, the 
Group changed its organizational structure of treasury since a Corporate Treasury was established instead of the TD of the subsidiaries that were finally suppressed. As a consequence, the Group got an single global treasury position, financial cost savings, and a more reliable control of its liquidity position.

On the other hand, the reengineering of $\mathrm{CM}$ processes to implement the treasury SAP R/3 module caused loss of jobs that in turn resulted in the loss of trust and loyalty of the employees for the company, and uncertainty between the employees who also experienced feelings of anguish, impotence, conformism and even resentment. In conclusion, Energy lost its paternalistic organizational culture. In this sense, we conclude that, based on our case study, the impacts of the analyzed organizational change on the human dimension of the organization depend on both the content of the change and the way in which the change is implemented. In the case of the TD of Energy, the human dimension wasn't considered by the people responsible for the implementation of SAPR/3 and this caused a higher resistance to the change. This lack of participation in the implementation of reengineering projects has been mentioned as a reason for the failure of such projects (Grover $e t$ al., 1995). However, in our case study, the implementation of SAP R/3 in the TD can't be classified as a failure as the Group got its objective. However, we can say that the negative repercussions of the change on the employees could have been minimized through the adoption of measures such as a wider communication or a higher participation of the employees in the reengineering project (Guha et al., 1997; Martinsons and Chong; 1999). These measures weren't present in Energy and they could have enabled "a more human reengineering" (Cooper and Markus, 1995).

Furthermore, the case of Energy has confirmed some significant aspects about the $\mathrm{CM}$ current evolution, such as the necessary relationship between Treasury and Accounting (Helliar, 1998), the higher orientation of the CM toward management tasks (Torre, 1998; Heywood, 1999), the reinforcement of the relationship between organizations and financial entities (Teigen, 2001), although with a lower number of them (MacDonald, 2001), and the trend in large business groups towards the CM centralization (Large, 2001; Mulligan, 2001).

In terms of future research, we see an opportunity to further analyse the organizational change generated by the process redesign to implement other IT 
systems in the TD such as the Internet banking or the workflow technology, as well as to analyze the contribution of these IT systems to the CM evolution. Likewise, we can concentrate further on the organizational change generated by the $\mathrm{CM}$ process outsourcing or the establishment of treasury shared services centres due to their current diffusion in business groups.

Specifically to the development of the research on reengineering, we should consider both the technological dimension of this change type and the organizational and human dimensions that complement it. In this respect, the combined consideration of these dimensions is scarcely present both in the professional environment, where the failure percentage of reengineering is situated between $50 \%$ and $70 \%$ of reengineering projects (Kim and Kim, 1998; Mayer and DeWitte, 1999) due mainly to the absence of a correct change management (Grover et al., 1995), and in the academic environment as the research is mainly focused on the technological dimension.

\section{REFERENCES}

BRANDMAN, J. (2000): "Streamlining the Treasury Function", Global Finance, vol. 14 , n. 8: 51-52.

BRAZZALE, J.; MILLIGAN, L. (1998): “Adding Value by Reengineering Treasury”, TMA Journal, vol. 18, n. 5: 6-12.

CHARRO, A.M.; ORTÍZ, J.F. (1996): "La Función de Tesorería en la Empresa. Banca Electrónica y Cash Management", Boletín de Estudios Económicos, vol. 51, n. 157: 129-164.

COOPER, R.; MARKUS, M.L. (1995): "Human Reengineering", Sloan Management Review, vol. 36, n. 4: 39-50.

DAVENPORT, T.H. (1993a): "Need Radical Innovation and Continuous Improvement?. Integrate Process”, Planning Review, vol. 21, n. 3: 6-12.

DAVENPORT, T.H. (1993b): Process Innovation: Reengineering Work through Information Technology. Harvard Business School Press, Boston.

DAVENPORT, T.H.; PEREZ-GUARDADO, M.A. (1999): "Process Ecology: A 
New Metaphor for Reengineering-Oriented Change", in D.J. Elzinga, T.R. Gulledge and C. Lee [eds.]: Business Process Reengineering: Advancing the State of the Art, Kluwer Academic Publishers, Massachusetts: 25-42.

EARL, M.J. (1994): “The New and the Old of Business Process Redesign", Journal of Strategic Information Systems, vol. 3, n. 1: 5-22.

GREIFER, N. (2001): "Revising Treasury Management Strategies", The American City \& County, vol. 116, n. 11: 12.

GROVER, V.; JEONG, S.R.; KETTINGER, W.J.; TENG, J.T.C. (1995): “The Implementation of Business Process Reengineering", Journal of Management Information Systems, vol. 12, n. 1: 109-144.

GUHA, S.; GROVER, V.; KETTINGER, W.J.; TENG, J.T.C. (1997): "Business Process Change and Organizational Performance: Exploring an Antecedent Model", Journal of Management Information Systems, vol. 14, n. 1: 119-154.

HAMMER, M.; CHAMPY, J. (1993): Reengineering the Corporation: A Manifiesto for Business Revolution. Harper Business, New York.

HELLIAR, C. (1998): "Management Control of the Treasury Function", Paper presented at the $21^{\text {st }}$ Annual Congress of the European Accounting Association, Antwerp, Belgium.

HEYWOOD, D. (1999): "Treasury Issues: Looking Around, Lookink Ahead", Australian CPA, vol. 69, n. 5: 36-37.

HEYWOOD, D. (2000): "The Treasurer Role: Looking for New Challenges", Australian CPA, vol. 70, n. 3: 36-38.

KIM, K.H.; KIM, Y.G. (1998): "Process Reverse Engineering for BPR: A FormBased Approach", Information \& Management, vol. 33, n. 4: 187-200.

LARGE, J. (1999): "How the Euro Has Helped Liquidity Management", Corporate Finance, n. 174: 38-47.

LARGE, J. (2001): “To Decentralize or Not to Decentralize", Corporate Finance, n. 198: 7-14. 
LÓPEZ, F.J. (1996): Manual del Cash Management. Cómo Obtener Beneficios Manejando Mejor su Dinero. Deusto, Bilbao.

MACDONALD, C. (2001): "Cash Managers without Frontiers", Latinfinance, n. 126: 27-29.

MAKELA, K. (1999): "Integration and Straight-Through Processing: The Platform for Strategic Treasury Management in the Third Millennium", Afp Exchange, vol. 19, n. 6: 60-63.

MALCOLM, I. (1999): "Shared Services: Re-run of an Old Movie or Part of a Continuing Evolution”, Management Accounting (CIMA), vol. 77, n. 11: 32-34.

MARTINO, R.L. (1998): "Treasury Technology: Caring for the Corporate Lifeblood", TMA Journal, vol. 18, n. 5: 64-66.

MARTINSONS, M.G.; CHONG, P.K.C. (1999): "The Influence of Human Factors and Specialist Involvement on Information Systems Success", Human Relations, vol. 52, n. 1: 123-152.

MAYER, R.J.; DeWITTE, P.S. (1999): "Delivering Results: Evolving BPR form Art to Engineering", in D.J. Elzinga, T.R. Gulledge and C. Lee [eds.]: Business Process Reengineering: Advancing the State of the Art, Kluwer Academic Publishers, Massachusetts: 83-130.

MULLIGAN, E. (2001): “Treasury Management Organisation: An Examination of Centralised Versus Decentralised Approaches", Irish Journal of Management, vol. 22, n. 1: 7-18.

PETTIGREW, A.M. (1997): "What is a Processual Analysis?", Scandinavian Journal of Management, vol. 13, n. 4: 337-348.

PHILLIPS, A.L. (1997): “Treasury Management: Job Responsibilities, Curricular Development and Research Opportunities", Financial Management, vol. 26, n. 3: 69-81.

POWELL, T.C.; DENT-MICALLEF, A. (1997): "Information Technology As Competitive Advantage: The Role of Human, Business, and Technology Resources”, Strategic Management Journal, vol. 18, n. 5: 375-405. 
SAGNER, J. (1997): Cashflow Reengineering. How to Optimize the Cashflow Timeline and Improve Financial Efficiency. Amacon, New York.

SANTOMÁ, J. (2000): Gestión de Tesorería. Gestión 2000, Barcelona.

SCAPENS, R. W. (1990): "Researching Management Accounting Practice: The Role of Case Study Methods", British Accounting Review, vol. 22, n. 3: 259281.

SCOTT, M. (1993): “The Virtual Treasury: Technologically-assisted Cash Management", Corporate Cashflow, vol. 14, n. 12: 28-31.

STODDARD, D.B.; JARVENPAA, S.L. (1995): "Business Process Redesign: Tactics for Managing Radical Change", Journal of Management Information Systems, vol. 12, n. 1: 81-107.

TEIGEN, L.E. (2001): “Treasury Management: An Overview”, Business Credit, vol. 103, n. 7: 23-24.

THONG, J.Y.L., YAP, C.S.; SEAH, K.L. (2003): “A Consolidated Methodology for Business Process Reengineering", International Journal of Computer Applications in Technology, vol. 17, n. 1: 1-15.

THURSTON, C.W. (2000): “Integrating Treasury Management”, Global Finance, vol. 14, n. 7 : 49-50.

TORRE, L.J. -Ed.- (1998): Manual de Tesorería. Instituto Superior de Técnicas y Prácticas Bancarias, Madrid.

VALLS, J.R. (1996): Fundamentos de la Nueva Gestión de Tesorería. Fundación Confemetal, Madrid.

WILSON, C. (2001): "Cash Management Services", Community Banker, vol. 10, n. $5: 22-25$.

YIN, R.K. (1989): Case Study Research: Design and Methods. Sage Publications, London. 